\title{
Artigos
}

\section{Sentidos produzidos por psicólogos que trabalham com cuidados paliativos no Sistema Único de Saúde (SUS) sobre o cuidar em cenários de morte e morrer}

Meanings of caring in settings of life and death produced by psychologists working with palliative care in Brazilian National Health System (SUS) about caring in settings of death and dying (abstract: p. 15)

Sentidos producidos por psicólogos que trabajan con cuidados paliativos en el Sistema Brasileño de Salud (SUS) sobre el cuidar en escenarios de muerte y del morir (resumen: p. 15)

Jerusa Pires Pozzada ${ }^{(a)}$

<jerusapozzada@yahoo.com.br> (iD)

Manoel Antônio dos Santos ${ }^{(b)}$

<masantos@ffclrp.usp.br> (ID)

Daniela Barsotti Santos ${ }^{(\mathrm{c})}$

<daniela.santos@furg.br> (iD

\author{
(a) Residência Integrada \\ Multiprofissional Hospitalar \\ com ênfase na Atenção à Saúde \\ Cardiometabólica do Adulto \\ (RIMHAS), Universidade Federal \\ do Rio Grande (FURG). Avenida \\ Itália, km 8, bairro Carreiros. Rio \\ Grande, RS, Brasil. 96203-900. \\ (b) Departamento de Psicologia \\ e Educação, Faculdade de \\ Filosofia, Ciências e Letras de \\ Ribeirão Preto, Universidade \\ de São Paulo. Ribeirão Preto, \\ SP, Brasil. \\ (c) Programa de Pós-Graduação em \\ Psicologia, Instituto de Ciências \\ Humanas e da Informação, \\ FURG. Rio Grande, RS, Brasil.
}

Cuidados paliativos (CPS) no Sistema Único de Saúde (SUS) devem ser realizados de modo integral e multidisciplinar na interface com usuário, família, cuidadores e equipe na aproximação à finitude humana. Objetivou-se descrever os sentidos sobre o cuidar nos cenários da morte e do morrer, produzidos por psicólogos que trabalham com CPs no SUS. Trata-se de pesquisa qualitativa construcionista social inspirada na descrição da produção de sentidos do cotidiano. Foram entrevistados quatro psicólogos que atuavam em atenção domiciliar, ambulatório de CPs e atenção hospitalar. Dois eixos temáticos foram construídos: "Os processos de trabalho e seus avessos" e "Nas proximidades da morte e do morrer". Destaca-se a importância do trabalho em equipe nos processos autoformativos; os desafios do trabalho com a morte e o morrer diante de limitações do cotidiano; e construções críticas e reflexivas do trabalho que promovem saúde mental.

Palavras-chave: Saúde do trabalhador. Profissional de saúde. Cuidados paliativos. Saúde mental. Saúde Pública.

Pozzada JP, Santos MA, Santos DB. Sentidos produzidos por psicólogos que trabalham com cuidados paliativos no Sistema Único de Saúde (SUS) sobre o cuidar em cenários de morte e morrer. Interface (Botucatu). 2022; 26 : e210581 https://doi.org/10.1590/interface.210581 


\section{Introdução}

De acordo com a Organização Mundial de Saúde, os cuidados paliativos (CPs) consistem em uma abordagem promotora da qualidade de vida dos pacientes considerados fora de possibilidades terapêuticas de cura e de seus familiares. Os CPs primam pelo manejo do sofrimento em suas variadas dimensóes, sejam elas física, psicossocial e espiritual, bem como a identificação precoce, a avaliação e o alívio da dor ${ }^{1}$.

No Brasil, o Sistema Único de Saúde (SUS) assegura o acesso aos CPs para todas as pessoas que vivenciam o adoecimento que ameaça a continuidade da vida. Recomenda-se que os CPs, no âmbito do SUS, aconteçam de modo integrado à Rede de Atenção à Saúde (RAS), com incentivo ao trabalho em equipe multidisciplinar baseado nos princípios da humanização da atenção à saúde. Os cuidados devem ser pautados em evidências científicas e necessitam assegurar o direito ao acesso equitativo a serviços efetivos pela abrangência da linha de cuidado e em todos os níveis de atenção. Tais diretrizes gerais dão contornos à integralidade dos $\mathrm{CPs}^{2-4}$.

Ainda são escassos os currículos que abordam o impacto da gestão de questóes relacionadas à morte e ao morrer na higidez psicológica dos profissionais da saúde. A carência pode ser ainda mais expressiva nos conteúdos voltados aos profissionais que atendem pessoas em situação de $\mathrm{CPs}^{5}$. Tal lacuna de formação de "quem cuida do cuidador" afeta a (re)produção do trabalho nos CPs, em dimensôes como a construção e manutenção do vínculo com o paciente e o reconhecimento de necessidades específicas de saúde mental.

Pesquisa sobre os sentidos produzidos por profissionais de equipes que atuam na atenção domiciliar $(\mathrm{AD})$ de idosos em CPs elencou as principais fontes de angústia, entre as quais se destaca a construção de sentido de se perceber elo entre o usuário vulnerável e o serviço de saúde. Os trabalhadores referiram o desafio de ajustar sua realidade emocional à da família e dos cuidadores ${ }^{6}$, em um cenário de alta densidade de demandas de saúde mental. Quando conseguem estabelecer essa sintonia, a construção de um bom vínculo serve como ponto de referência para um cuidado humanizado. No entanto, em certas circunstâncias, esse esforço pode afetar a saúde mental do profissional.

Estudo evidenciou que os profissionais de saúde, como médicos, enfermeiros e assistentes sociais, encontram barreiras para identificar o risco de suicídio ${ }^{7}$ e problemas de saúde mental ${ }^{8}$ em pacientes com câncer. As barreiras percebidas incluem: falta de treinamento e de conscientização; dificuldade em diferenciar a tendência suicida de outros sofrimentos psíquicos, menor tempo com os pacientes, medo de perguntar sobre suicídio e falta de recursos pessoais para lidar com pacientes com potencial suicida. Os relatos dos profissionais sobre tais barreiras são preocupantes, dado o risco aumentado de suicídio entre pacientes oncológicos?.

O encontro com a finitude permeia a rotina do profissional que atua nos CPs muito antes de se instalar o cenário de morte iminente, considerando que, na concepção atual, o ponto de partida para a implementação desses cuidados se dá desde o diagnóstico de uma condição grave ameaçadora da continuidade da vida ${ }^{2}$. Um dos maiores desafios enfrentados é assegurar as condiçôes de conforto emocional quando se está nas proximidades da morte. O conceito de Boa Morte é parte do ideário dos CPs e pode ser definido como uma morte acompanhada de dignidade e sem sofrimento. Para que o desfecho da vida ocorra com o 
máximo de dignidade possível, é necessário que se evitem tratamentos heroicos - isto é, com fins curativos e que não beneficiam a qualidade de sobrevida do paciente em situação de finitude, contribuindo apenas para incrementar o sofrimento.

Dada a importância de se investigar como o sentido de Boa Morte é negociado nas práticas discursivas que medeiam a relação profissional-paciente, foi formulada a seguinte questão de pesquisa: que sentidos sobre o cuidar têm sido construídos no cotidiano da atuação em CPs por profissionais da Psicologia inseridos nos serviços do SUS?

Em vista dessas consideraçóes, este estudo teve por objetivo descrever os sentidos sobre o cuidar nos cenários da morte e do morrer, produzidos por psicólogos que trabalham com CPs em diferentes contextos de práticas do SUS.

\section{Método}

Trata-se de uma pesquisa de abordagem qualitativa, amparada na perspectiva construcionista social e focada na descrição e compreensão dos sentidos produzidos no cotidiano. O uso dos métodos qualitativos em pesquisas das Ciências Humanas e Sociais na Saúde permite compreender as coconstruções de significações e realidades pelas pessoas em contextos situados. Essa perspectiva epistemológica leva em consideração a complexidade do mundo humano, além de problematizar o lugar do pesquisador e analisar sua influência na investigação e em seus resultados ${ }^{10}$.

Alinhando-se ao debate pós-modernista, no movimento do construcionismo social, a produção de sentidos é situada a partir das práticas discursivas. $O$ pesquisador adota uma postura de ruptura com o modo tradicional de produzir ciência e busca ultrapassar a dualidade sujeito-objeto ao situar o conhecimento nos processos de interação social. O processo de produção de sentidos é analisado segundo as práticas discursivas do cotidiano, definidas como práticas sociais que envolvem pessoas engajadas em constantes jogos de trocas simbólicas em um espaço de interpessoalidade que também é socialmente construído ${ }^{11}$. Embora seja enfatizada a perspectiva da Psicologia Social, a produção de sentidos no movimento do construcionismo social é necessariamente interdisciplinar, o que torna esse vértice pertinente para abordar o campo discursivo dos CPs, considerando o seu caráter interdisciplinar.

Foram convidados a participar da pesquisa quatro psicólogos que atuavam em CPs em uma cidade de porte médio do extremo sul do Rio Grande do Sul. Os critérios para inclusão dos profissionais neste estudo foram: ser psicológo(a), trabalhar em CPs e atuar diretamente com a população em equipamentos do SUS há pelo menos um ano. Em relação ao critério utilizado para definição do número de participantes, preliminarmente, foram mapeados os cenários de práticas do psicólogo em CPs no SUS no município. Constatou-se a presença de um profissional inserido no contexto hospitalar, um no ambulatório de CPs e dois em serviços de $\mathrm{AD}$. Todos foram convidados e aceitaram colaborar com o estudo, de modo que o número de participantes corresponde ao universo delimitado para a pesquisa.

A escolha do instrumento utilizado para a coleta de dados se deu em conformidade com o referencial teórico-metodológico socioconstrucionista, que valoriza a realização de entrevistas em profundidade como contexto dialógico propício para capturar a produção e negociação de sentidos. As entrevistas foram realizadas individualmente, em sala 
reservada do serviço, de acordo com a disponibilidade do participante. A conversação foi mediada por um roteiro temático composto por duas partes: uma para capturar dados para caracterização sociodemográfica dos participantes (idade, naturalidade, religião, entre outros) e outra com questôes sobre a trajetória de formação e atuação profissional, rotina de trabalho, funçôes exercidas na equipe de CPs, aspectos relacionados ao vínculo psicólogo-paciente e sentidos sobre a Boa Morte, o viver e o morrer.

As entrevistas aconteceram nos meses de agosto e setembro de 2018 com duração média de 120 minutos. Foram audiogravadas e, posteriormente, transcritas na íntegra e literalmente, constituindo o corpus da pesquisa. A análise seguiu os seguintes passos: (1) a partir de leituras exploratórias das transcriçôes, as narrativas foram inicialmente sistematizadas pela delimitação de temáticas amplas, guiadas pelo objetivo traçado pelo estudo; (2) codificação e recorte de fragmentos de falas em árvores de associação de ideias; e (3) interpretação do material segundo o referencial teórico-metodológico, destacando-se as informaçóes centrais obtidas e verticalizadas por meio de eixos temáticos que aglutinaram os sentidos produzidos ${ }^{12}$.

O projeto foi aprovado pelo Comitê de Ética em Pesquisa da instituição a qual os autores do estudo estão vinculados, parecer no 2.788 .553 , em conformidade com as diretrizes da resolução 466/2012 do Conselho Nacional de Saúde.

\section{Resultados e discussão}

Participaram do estudo quatro psicólogos - três mulheres e um homem -, com idades entre 33 e 52 anos. Três eram naturais da região Sul e um do Sudeste. Eles professavam diferentes crenças: dois eram adeptos de práticas espirituais orientais, um era católico e o outro referiu não ter crença espiritual ou religiosa. Três entrevistados haviam concluído ao menos uma pós-graduação lato sensu e/ou stricto sensu. O tempo de atuação profissional variou entre sete e 26 anos. Com relação ao tempo de trabalho em CPs no SUS, um entrevistado afirmou atuar havia cinco anos, dois há dois anos e meio e outro há mais de um ano. Os cenários de práticas variaram, sendo que um dos participantes atuava no contexto hospitalar, um em ambulatório de CPs e dois em serviços de AD.

Foram construídos dois eixos temáticos, que descrevem os sentidos produzidos no cotidiano dos CPs: "Os processos de trabalho e seus avessos" e "Nas proximidades da morte e do morrer”.

\section{Os processos de trabalho e seus avessos: "sem nenhum preparo, nem emocional, nem físico"}

Esse eixo temático concentra as descrições de sentidos produzidos sobre os processos de trabalho nos distintos cenários de prática, acompanhados das ressonâncias dos sentidos sobre o trabalho da psicologia produzidos por outros profissionais da equipe. Inclui também as descriçóes sobre as funçóes da Psicologia nos CPs, a preparação profissional e pessoal para o trabalho, bem como atributos pessoais que são esperados do profissional nos CPs. 
O delineamento dos processos de trabalho no modo multiprofissional constitui um dos pressupostos básicos dos $\mathrm{CPs}^{13}$. Mesmo engajados em cenários distintos, todos os entrevistados relataram atuar em equipes multiprofissionais compostas por um conjunto amplo de especialidades, que incluem médicos, enfermeiros, técnicos de enfermagem, psicólogo, terapeuta ocupacional, dentista, assistente social, fisioterapeuta, nutricionista, educador físico e capelão. Dois afirmaram que também oferecem consultorias para outras equipes.

$\mathrm{O}$ round foi mencionado pela maioria como um momento privilegiado em que a equipe compartilha a discussão dos casos de modo integrado, servindo também como espaço para aprimoramento da formação técnico-pedagógica. Apenas um participante afirmou que, devido à rotina do ambulatório, os profissionais encontravam formas alternativas de trocar informaçóes sobre os atendimentos realizados em contextos informais, ao se encontrarem nos corredores do hospital.

Todos qualificaram como boa e amistosa a relação estabelecida entre os membros da equipe, baseada em respeito e amparo mútuo, especialmente quando se faz necessário o trabalho colaborativo nos momentos difíceis. Os entrevistados valorizaram o compartilhamento de conhecimentos como recurso favorecedor de um bom cuidado. No entanto, a despeito do acolhimento das distintas visões e epistemologias sobre o cuidado à saúde, os participantes reconheceram o predomínio do modelo biomédico e de certa desvalorização das dimensões psíquicas, sociais e culturais imbricadas no processo saúde-doença-cuidado. Um entrevistado destacou a necessidade de se fazer uma "tradução" das diferentes linguagens que se entrecruzam no campo da operacionalização da multidisciplinaridade.

[...] muitas vezes, os outros profissionais acham que os psicólogos "floreiam" muito. [...] [A compreensão dos demais] depende de como a gente trabalha e de como a gente consegue traduzir isso que a gente está observando para os outros profissionais da equipe. Não acho que seja nossa função traduzir isso, mas se a gente consegue, facilita o trabalho. (P3)

Diferentes sentidos são outorgados ao que seriam os alcances e limites percebidos da atuação do psicólogo nos CPs. Esses sentidos são produzidos de acordo com o cenário que dá contorno às práticas do cuidado. Para o profissional vinculado ao ambulatório de CPs, o trabalho do psicólogo cessaria com a morte do paciente. Já o psicólogo que atua no hospital apontou que um outro desfecho pode ser o encaminhamento para outro serviço do paciente com progressão de doença mais avançada, como o serviço de $\mathrm{AD}$. Já para os profissionais que atuam na $\mathrm{AD}$, o trabalho do psicólogo deve prosseguir mesmo após o óbito, por meio da oferta de apoio psicológico aos familiares enlutados, na medida em que se configurou anteriormente com eles o vínculo, por meio da aliança de trabalho estabelecida ao longo do tratamento.

No que se refere às rotinas de trabalho, os participantes descreveram sua atuação por meio da interação com os diversos atores envolvidos nesse processo. $\mathrm{O}$ trabalho do psicólogo envolve estudar e analisar processos intrapessoais e relaçóes interpessoais ao desenvolver uma compreensão das ações individuais e grupais nos contextos em que essas relaçôes acontecem, primando pelo esforço de facilitação da comunicaçãa $0^{5,13}$. 
Para os entrevistados, auxiliar paciente e familiares a darem sentido e encaminharem algumas de suas "pendências” são tarefas nobres, que devem ser integradas à assistência em CPs como gestos finais da existência ${ }^{14,15}$. O psicólogo também deve favorecer o resgate da trajetória de vida da pessoa e daqueles que estão ao seu redor nos momentos finais da vida, entender como foram e ainda são estabelecidas as relaçóes com sua rede pessoal significativa, quem são as pessoas que fazem parte da sua rede de apoio, bem como seus desejos, limites e possibilidades de realizá-los no tempo relativamente breve de que dispõem. Também se faz necessário investigar o grau de envolvimento e intimidade que o paciente tolera ou deseja, que é modulado pelas alternativas terapêuticas que lhe são oferecidas pela equipe, assim como por questóes relacionadas ao seu prognóstico ${ }^{16}$.

[...] um dos trabalhos mais importantes em Cuidados Paliativos é eu ir à casa do paciente e avaliar se ele sabe o que ele tem e se ele quer saber. (P3)

Segundo os participantes, como o câncer é uma doença crônico-degenerativa altamente estigmatizante e estigmatizada, a dimensão do conhecimento do status individual transcende os aspectos cognitivos, pois inicialmente envolve questóes emocionais e os sentidos que são produzidos pela pessoa ao se relacionar com o fato impactante de estar gravemente adoecida e ser considerada sem perspectiva terapêutica. A doença é um marcador simbólico da fronteira entre "saber" e (não) “querer” saber, o que introduz a diferença entre desejo e suportabilidade no admitir a consciência clara da própria finitude. Implica, portanto, um estreitamento do horizonte existencial, o que solicita um posicionamento ético do psicólogo. A clínica da terminalidade envolve um contínuo interjogo de forças, que se apresentam na forma de paradoxos existenciais (vida-morte, esperança-aniquilamento). O trabalho é significado pela oferta de uma escuta sensível e qualificada, que busca propiciar condições para que o outro possa estar face a esse limite humano inexorável sentindo-se menos desprotegido e desconfortável, de modo a poder suportar os impactos das diversas perdas vitais acumuladas na aproximação à finitude, conferindo sentidos a cada uma delas. Esses sentidos são sempre coproduzidos e compartilhados na rede pessoal.

O trabalho relatado pelos participantes também abrange o acompanhamento e apoio emocional da família, que é impactada, cada uma à sua própria maneira, nos diferentes estágios do adoecer do ente querido, sendo afetada tanto do ponto de vista psíquico quanto social, econômico e existencial ${ }^{16}$. Para tanto, é necessário manter um "olhar sistêmico, holístico e perspicaz" para as necessidades subjetivas dos familiares (P3). Estes são posicionados pelos entrevistados como “aliados”, cuidadores coadjuvantes e, ao mesmo tempo, como pessoas que também demandam cuidados. Os entrevistados referem que, para assumirem suas funçóes como cuidadores, os familiares deveriam receber algum tipo de preparo anterior.

Mas todo esse apoio de dar alimentação, de fazer troca de fralda, de dar banho, isso é responsabilidade dos familiares. Muitas vezes, a gente observa que os familiares são colocados nessa função de cuidadores sem nenhum preparo, nem emocional, nem físico. (P4) 
Os profissionais muitas vezes são hábeis em diagnosticar a premente necessidade de preparar os familiares nas artes e nos desafios do cuidar domiciliar do paciente oncológico, para que possam suprir as necessidades de seus entes de maneira apropriada, considerando que as demandas tendem a se acentuar gradualmente à medida que a doença avança e o quadro clínico se agrava ${ }^{16}$. Contudo, alguns participantes parecem não reconhecer que é parte de seu papel profissional prover esse "preparo físico e emocional" aos familiares, preferencialmente em açôes integradas e coordenadas com a saúde.

Os participantes foram questionados sobre características que consideravam imprescindíveis para o trabalho dos psicólogos nos CPs. A empatia foi um atributo reiterado em todos os relatos. A maioria considerou importante adquirir conhecimento teórico-técnico específico, evidenciando também preocupação em se manterem atualizados em relação aos conteúdos e avanços produzidos na área como estratégias para qualificar o fazer profissional. Os entrevistados também mencionaram outras qualidades desejáveis, como sensibilidade; compaixão; perspicácia; gostar do que faz; e estar bem emocional e psicologicamente.

Dois dos entrevistados comentaram sobre a importância de "ser humilde" no exercício do cuidado emocional e na compreensão da "dureza da natureza de seu trabalho", que por vezes não será reconhecido como eficaz e tampouco valorizado ou recompensado. Assim, a clínica da terminalidade é significada como árdua e altamente exigente e seletiva em termos dos atributos de personalidade que seriam requeridos para um adequado exercício do cuidar, na medida em que o acompanhamento do morrer vai confrontar o psicólogo com questôes existenciais ${ }^{17,20}$. Estudos anteriores exploraram esse desafio na perspectiva de médicos e enfermeiros, ao se verem frente à situação de terminalidade dos pacientes, encontrando resultados semelhantes ${ }^{18,19}$. Estar em face de situaçóes-limite contribui para que os profissionais modulem os significados pessoais da morte e do morrer.

Os entrevistados percebem diferenças entre a formação recebida durante a graduação e a realidade do trabalho tal como se apresenta no cotidiano, principalmente com relação ao setting disponível para o atendimento. Por exemplo, quando o psicólogo "sai a campo" para realizar $\mathrm{AD}$, sente-se pouco preparado e equipado para oferecer uma intervenção potente em settings distintos dos tradicionais. De início isso pode despertar uma sensação desconfortável de "estar deslocado" no desempenho de sua prática, o que o faz se sentir desprotegido ao abandonar o (ilusório) senso de segurança e conforto inspirado pelo consultório ou pela instituição hospitalar ${ }^{19}$.

Por outro lado, tais desafios fazem com que os psicólogos busquem desenvolver estratégias para se ajustarem nos diferentes cenários de atenção. Três comentaram sobre situações vividas, nas quais eles deliberadamente modificaram o setting no intuito de tornar o atendimento mais humanizado. Um participante ilustrou essa questão com o fato de seu atendimento não ter um tempo previamente estipulado. Essa não padronização é entendida como um aspecto técnico que contraria os preceitos de um modelo teórico reiterado e reificado durante o processo de formação profissional ${ }^{17,20,21}$. 
O local do atendimento também requer especial atenção, pois a escuta acontece, muitas vezes, no quarto do hospital ou da residência, onde nem sempre é possível assegurar as condiçôes ideais de respeito à privacidade. O psicólogo se senta à beira do leito, na presença ou não de outras pessoas, ainda que primando pela preservação da intimidade, conforto e bem-estar subjetivo da pessoa assistida.

A gente vê algo como um sorriso, tu levar uma alegria para a casa das pessoas, como é legal, sabe? A maioria dos pacientes fica numa felicidade com a visita! E outra coisa é o toque, porque eu, no consultório, [...] não tocava nos pacientes. Agora eu abraço todo mundo, tomo café, beijo os pacientes. Tem pacientes que são muito afetivos. Dou minha mão se o paciente chora. Então, tudo aquilo que não podia fazer na teoria, na prática tu vê como faz diferença o fato de tu ser um ser humano. (P3)

Esse excerto de fala aponta de modo eloquente o quanto o profissional muitas vezes tem de descontruir certos estereótipos associados ao modelo clínico aprendido. Os relatos estabelecem uma distinção entre a prática psicoterápica com setting delimitado, comumente aprendida nas clínicas psicológicas universitárias e amplamente reproduzida no âmbito privado dos consultórios, e a escuta em uma psicoterapia realizada nos ambientes de CPs. Um participante destacou que o paliativista necessita ter afinidade com o campo da Psicologia Social.

[...] porque o trabalho em CP também tem questóes de Psicologia Social [...] e se você não entende esses processos de vulnerabilidade, as questóes psicossociais que ali estão postas, você não vai conseguir fazer um trabalho que seja efetivo. (P4)

Diante dos sentidos coconstruídos pelos participantes sobre o trabalho com os CPs, os cuidados se inserem em um horizonte ético-político-existencial, conforme resta visibilizado no próximo eixo temático.

\section{Nas proximidades da morte e do morrer: "as coisas que a gente não consegue solucionar"}

Nesse eixo temático são agrupados os sentidos produzidos pelos profissionais ao relatarem encontrar em seu trabalho desafios relacionados ao contato contínuo com a dramática da morte e do morrer. Foram evocadas lembranças de experiências difíceis de serem processadas emocionalmente. $\mathrm{Na}$ visão dos entrevistados essas dificuldades são recorrentes quando se atua nos CPs. As principais barreiras elencadas foram: a dor impossível de ser completamente dimensionada e controlada - pois envolve também aspectos psicossociais e existenciais -; a visita da morte presenciada de perto e diuturnamente; e o desafio de lidar com os próprios limites perante situaçóes que não se consegue solucionar. Segundo a literatura, o profissional de saúde experimenta, em seus processos subjetivos, sua própria fragilidade, vulnerabilidade, medos e incertezas, muitas vezes sem que consiga vislumbrar caminhos alternativos ou possibilidades de compartilhar seus sentimentos ${ }^{17,21,22}$. 
Lidar com toda essa vulnerabilidade, principalmente, das coisas que a gente não consegue solucionar, às vezes é muito difícil [...]. Mas lidar com a exclusão social e a vulnerabilidade desses pacientes às vezes é ainda mais exaustivo. (P4)

Dois entrevistados ressaltaram a importância de observar atentamente os demais profissionais da equipe em atuação, pois o psicólogo também é responsável por fornecer orientaçôes de manejo das relaçóes estabelecidas entre os membros da equipe, pacientes e familiares, tendo a morte, o sofrimento e a dor como eixos balizadores que redimensionam constantemente seus saberes e fazeres compartilhados nesse cenário. Em tais condições é necessário identificar as circunstâncias que podem produzir desequilíbrios emocionais e adoecimentos em cada profissional da equipe, bem como os fatores fortalecedores e indutores de resiliência. Estudo mostra que as dificuldades que alguns profissionais encontram ao lidar com as adversidades do cotidiano assistencial contribuem para desencadear situaçóes de estresse, convertendo-se em sentimento de impotência, frustração e revolta ${ }^{23}$.

Ao acolher um paciente nos CPs, a equipe atuará no sentido de proporcionar uma estrutura física, social, emocional e espiritual para que o período do final de vida seja vivenciado da forma mais digna e aceitável possível, com foco na promoção da qualidade de vida. Uma leitura da biografia da pessoa em situação de terminalidade deve valorizar a expressão de suas emoções suscitadas pelo modo como ela se relaciona com a doença. Deve-se facilitar as condiçôes para que ela possa ressignificar, por meio dos sentidos construídos com seus gestos finais, sua trajetória de construção de vínculos sociais e afetivos, visando à elaboração da Boa Morte ${ }^{14}$.

Quando a gente está falando de morte ou sobre terminalidade, a gente está falando de vida. Como que o paciente viveu a sua vida, quais são os valores culturais que ele atribui, os valores espirituais, valores familiares? O que é importante e relevante para ele? Quais foram as conquistas que ele teve, quais foram as derrotas que ele teve também, para entender como que ele lida com tudo isso. Porque isso tudo vai direcionar seu processo. (P1)

O conhecimento é produto de um processo de interação social e historicamente situado, uma vez que sujeito e objeto são construçôes sócio-históricas que precisam ser problematizadas e dessencializados para que se possa reconstruir a noção de realidade. Os sentidos produzidos sobre o trabalho do psicólogo na clínica dos CPs são coconstruídos com a pessoa atendida e se articulam com as práticas discursivas circunscritas socialmente pela cultura. Desse modo, o conhecimento sobre o morrer é uma construção social. Por isso o morrer será vivenciado de forma singular dependendo do lugar que cada indivíduo ocupa em sua cultura e de sua posição na organização social e familiar, nos limites de seu contexto relacional ${ }^{17}$. Porém, nas descriçôes obtidas dos participantes, os sentidos outorgados aos atos finais da vida da pessoa atendida têm um foco individual. Isto é, são influenciados por aspectos do funcionamento individual, temperados pelas experiências pregressas de perdas vivenciadas pelo sujeito que está em processo de finitude. 
(2)

Nota-se, assim, uma tendência a valorizar fatores circunscritos à história pessoal. Nesse contexto, caberia ao psicólogo articular as várias peças do quebra-cabeças biográfico, constituído pelas experiências que imprimiram significados únicos na construção do itinerário daquela vida vivida e cumprida junto aos seus. Uma das condições necessárias é apoiar a pessoa a encontrar o fio condutor que lhe permita amarrar o sentido da própria existência que ora está por findar.

Se tu tens uma pessoa que teve uma vida de muitas privaçóes, de muitas dificuldades, como que ele vai encarar esse processo de morte? Se ele teve vinculaçóes positivas, relaçóes familiares, um suporte familiar legal, ele vai querer estar perto dessa família? [...] Ou, se ele foi uma pessoa que viveu sozinha a vida inteira, preocupado apenas com os aspectos materiais, em adquirir coisas... E aí, como é que vai passar por esse processo? (P1)

Os profissionais compartilharam diferentes experiências vividas no cotidiano dos CPs e coconstruíram relatos densos, que descrevem como o processo de acompanhar pessoas nas proximidades da morte e do morrer se desenvolve a partir de uma rotina de trabalho que privilegia os aspectos subjetivos e intersubjetivos envolvidos nesse cenário. Destaca-se o respeito à autonomia e ao protagonismo ao acompanhar o paciente em seu caminhar rumo ao final da vida, mantendo-se sensível aos valores e sentidos construídos por ele, sem induçôes ou imposiçốes por parte do psicólogo, de seus próprios pontos de vista ${ }^{24}$.

Eu acho que conseguir compreender, junto com o paciente o que para ele significa a Boa Morte [...]. Então, eu acho que quebrar barreiras para conseguir conversar sobre isso com ele de uma forma franca é primordial. E entender com ele e com os familiares como é que vai ser essa Boa Morte [...]. Tentar não fazer com que as minhas impressóes, o meu conceito de Boa Morte contamine o paciente, mas que ele próprio construa a trajetória dele. (P4)

Viabilizar um espaço para a expressão da espiritualidade também faz parte dos princípios que norteiam o trabalho em CPs, de acordo com os participantes, que reconheceram que esse recurso pode auxiliar na construção de um cuidado humanizado para acolher o sofrimento inerente ao avanço da doença ${ }^{2426}$. Os entrevistados também mencionaram a espiritualidade como uma das dimensões existenciais que mais se presentifica na situação de terminalidade e ofereceram diferentes perspectivas em relação a esse tema.

[...] é por esse lado de acolher, porque tem pacientes que, por mais que eles saibam que vão morrer, até o último momento eles têm alguma esperança. Não esperança de viver, mas esperança relacionada a vários tipos de crenças: de que vão para um lugar melhor, de que o sofrimento vai acabar. (P1) 
Em muitos casos, no intuito de poupar a pessoa enferma do sofrimento, a família oculta informaçốes cruciais sobre o diagnóstico ou prognóstico ${ }^{14}$, especialmente quando o tratamento não oferece a resposta esperada e a doença segue seu curso natural progressivo e refratário às intervençôes implementadas. Por essa razão é crucial que o psicólogo trabalhe em constante interlocução com os atores envolvidos nesse cenário, mediando diálogos e situaçôes conflituais entre paciente, familiares e equipe de saúde, alinhavando pontos de amarração que contemplem, principalmente, aquilo que a pessoa adoecida almeja em seu final de vida.

Os familiares devem também entender e respeitar quando o paciente tem autonomia para decidir. Por mais que sejam discordantes, o paciente é quem decide. [...] tem, a questão muito prejudicial, quando a gente não consegue fazer um trabalho a tempo com aquela família que decretou o sigilo, [...] sobre a possibilidade de morte. (P1)

Lidar com a morte interdita é um dos desafios enfrentados pelo psicólogo paliativista. Promover a autonomia e zelar pelo protagonismo do sujeito em relação ao próprio morrer são vetores que estão diretamente relacionados com a promoção da dignidade da pessoa em face da morte, sendo o cerne mesmo da Boa Morte. Nesse sentido, compreender os desejos da pessoa em final de vida, juntamente com sua família, é de extrema importância. Muitas vezes, o familiar tem dificuldade de assimilar que cabe ao paciente a decisão de como serão os arranjos relativos à sua morte ${ }^{4}$. Cabe ao familiar apoiar e aceitar as escolhas feitas por seu ente. Nesse contexto, o psicólogo lidará não apenas com as fantasias e desejos de imortalidade, mas também com o anseio coletivo e demasiado humano de permanecer vivos.

[...] nós, profissionais de saúde, temos uma coisa muito prescritiva. A gente acha que sabe o que é melhor para o paciente [...], o grande desafio é justamente sair dessa postura e fazer com que os demais profissionais também saiam. Ele [o paciente] sabe aquilo que é melhor para ele ou a gente tem de ajudá-lo a descobrir o que é melhor para ele [...] fazer esses encerramentos. (P4)

O esforço de amparar o paciente na hora decisiva em que ele se despede da vida é uma tarefa singular. Parteiro às avessas, o psicólogo ajuda o outro a se retirar do palco da vida e a fechar a cortina no último ato de sua existência. Quando finalmente cair o pano, o processo do morrer, se devidamente acompanhado por toda a equipe de saúde, pode ter sua dramaticidade atenuada com a incorporação de sentidos positivos, que reverberam a possibilidade de se dignificar o final da vida, partindo em $\mathrm{paz}^{14,27}$. 


\section{Considerações finais}

Foram descritos os sentidos produzidos sobre o cuidar, como parte do fazer do psicólogo nos cenários da morte e do morrer, destacando as potências e os limites desse trabalho. A integralidade dos CPs no âmbito do SUS depende tanto de sua articulação com a RAS quanto da qualidade da atenção oferecida pela equipe multidisciplinar. Nessas dimensóes, este estudo destaca o psicólogo enquanto profissional que atua, assim como os demais atores envolvidos em tal contexto, como elemento articulador de demandas e ações coordenadas para suprir os cuidados.

Os achados acerca dos sentidos sobre o cuidar em diferentes cenários da morte e do morrer, produzidos pelos psicólogos a partir de suas práticas no SUS, ampliam o entendimento sobre os processos de trabalho em equipe interdisciplinar. $\mathrm{O}$ cuidar nesse contexto solicita investimento em educação permanente, que incorpore, além de conhecimentos teóricos e técnicos, habilidades relacionais e emocionais específicas.

Nos sentidos engendrados sobre o fazer psicológico em contextos de aproximação com a finitude humana, ficaram explícitas as rupturas que essa prática instaura com os sentidos culturalmente construídos sobre o trabalho "tradicional" da psicologia. O cotidiano da atuação revela as limitaçóes dos modelos consagrados de atuação, centrados em uma visão patologizante e individualista do comportamento humano. Enfrentar esses limites implica na necessidade de superação dessa concepção dominante de indivíduo como totalidade autocontida, o que nos convida a tecer um processo reflexivo e crítico que maximize as condições de promoção da saúde mental, voltadas inclusive para o psicólogo.

Esta investigação apresenta algumas limitações, como o fato de ter sido realizada em um único contexto de um município situado em uma região específica do Brasil. Considerando a dimensão continental do país, são necessários novos estudos com maior abrangência e que captem as distintas realidades, considerando as enormes disparidades regionais e a profunda desigualdade social que caracterizam a sociedade brasileira.

O estudo traz como inovação a preocupação com a elucidação dos sentidos produzidos sobre o fazer do psicólogo que atua com equipes em diferentes cenários dos CPs vinculados ao SUS. Esse conhecimento é relevante e deve ser incorporado ao conjunto de indicadores que permitem circunscrever as potências e limitaçóes do trabalho da Psicologia no movimento paliativista e no campo da terminalidade. Ao se considerar a formação para o trabalho com a saúde mental do psicólogo enquanto profissional da saúde, devem ser incorporadas as estratégias bem-sucedidas utilizadas por esses trabalhadores na tentativa de superar as barreiras encontradas no manejo dos aspectos emocionais e comportamentais dos pacientes e de seus familiares.

Também devem ser considerados os potenciais impactos da (re) produção do trabalho em CPs na constituição subjetiva do profissional. Uma estratégia que parece ser promissora é estimular sua autonomia e criatividade para a busca de estratégias inovadoras e para a reformulação contínua e constante de seus processos de trabalho. Espera-se, assim, que este estudo contribua com subsídios para o planejamento de açôes e elaboração de políticas em saúde do trabalhador que conduzam ao aperfeiçoamento tanto da formação quanto da atuação do psicólogo como trabalhador da saúde. 


\section{Contribuição dos autores}

Todos os autores participaram ativamente de todas as etapas de elaboração do manuscrito.

\section{Conflito de interesse}

Os autores não têm conflito de interesse a declarar.

\section{Direitos autorais}

Este artigo está licenciado sob a Licença Internacional Creative Commons 4.0, tipo BY (https://creativecommons.org/licenses/by/4.0/deed.pt_BR).

\section{(cc) BY}

\section{Editora}

Denise Martin

Editor associado

Moisés Romanini

\section{Submetido em}

$18 / 08 / 21$

Aprovado em

$14 / 09 / 21$

\section{Referências}

1. World Health Organization. WHO Definition of Palliative Care [Internet]. Geneva: WHO; 2020 [citado 22 Abr 2020]. Disponível em: https://www.who.int/cancer/ palliative/definition/en/2020

2. Brasil. Ministério da Saúde. Resolução no 41, de 31 de Outubro de 2018. Dispóe sobre as diretrizes para a organização dos cuidados paliativos, à luz dos cuidados continuados integrados, no âmbito Sistema Único de Saúde (SUS). Diário Oficial da União. 31 Out 2018.

3. Arruda-Colli MNF, Perina EM, Mendonça RMH, Santos MA. Intervenção psicológica com familiares enlutados em oncologia pediátrica: revisão da literatura. Psicol Teor Prat. 2015; 17(2):20-35.

4. Arruda-Colli MNF, Sansom-Daly U, Santos MA, Wiener L. Considerations for the cross-cultural adaptation of an advance care planning guide for youth with cancer. Clin Pract Pediatr Psychol. 2018; 6(4):341-54. 
5. Kovács MJ. Educação para a morte: temas e reflexões. São Paulo: Casa do Psicólogo/ FAPESP; 2003.

6. Marques FP, Bulgarelli AF. Os sentidos da atenção domiciliar no cuidado ao idoso na finitude: a perspectiva humana do profissional do SUS. Cienc Saude Colet. 2020; 25(6):2063-72.

7. Granek L, Nakash O, Ben-David M, Shapira S, Ariad S. Oncologists', nurses', and social workers' strategies and barriers to identifying suicide risk in cancer patients. Psychooncology. 2018; 27(1):148-54.

8. Granek L, Nakash O, Ariad S, Shapira S, Ben-David M. Mental health distress: oncology nurses' strategies and barriers in identifying distress in patients with cancer. Clin J Oncol Nurs. 2019; 23(1):43-51.

9. Santos MA. Câncer e suicídio em idosos: determinantes psicossociais do risco, psicopatologia e oportunidades para prevenção. Cienc Saude Colet. 2017; 22(9):3061-75.

10. Santiago-Delefosse M, Carral MR. Recherche qualitative, sciences sociales et humanines, et psychologie: des paradigmes em concurrence. In: Santiago-Delefosse M, Carral MR, organizadores. Les méthodes qualitatives em psychologie et sciences humaines de la santé. Paris: Dunod; 2017. p 7-32.

11. Spink MJ, Lima H. Rigor e visibilidade: a explicitação dos passos da interpretação. In: Spink MJ, organizadora. Práticas discursivas e produção de sentidos no cotidiano: aproximaçốes teóricas metodológicas. São Paulo: Cortez; 2000. p. 93-122.

12. Menezes RA. Em busca da Boa Morte: a antropologia dos cuidados paliativos. Rio de Janeiro: Fiocruz, Garamond; 2008.

13. Stenzel GQL, Paranhos ME, Ferreira VRT, Borges RV. A formação do psicólogo hospitalar. In: Stenzel GQL, Paranhos ME, Ferreira VRT, organizadores. A psicologia no cenário hospitalar. Porto Alegre: EdiPUCRS; 2012. p. 27-37.

14. Menezes CNB, Passareli PM, Drude FS, Santos MA, Valle ERM. Câncer infantil: organização familiar e doença. Rev Mal-Estar Subj. 2007; 7(1):191-210.

15. Oliveira EA, Santos MA, Mastropietro AP. Apoio psicológico na terminalidade: ensinamentos para a vida. Psicol Estud. 2010; 15(2):235-44.

16. Ponte ACSLC, Pais-Ribeiro JL. O bem-estar em cuidados paliativos: perspectiva do doente versus profissionais de saúde. Psicol Saude Doenças. 2014; 15(1):137-53.

17. Mastropietro AP, Oliveira EA, Santos MA. A clínica da terminalidade. Rev CETO. 2008; 11(11):18-25.

18. Santos MA, Aoki FCOS, Oliveira-Cardoso EA. Significado da morte para médicos frente à situação de terminalidade de pacientes submetidos ao Transplante de Medula Óssea. Cienc Saude Colet. 2013; 18(9):2625-34.

19. Santos MA, Hormanez M. Atitude frente à morte em profissionais e estudantes de enfermagem: revisão da produção científica da última década. Cienc Saude Colet. 2013; 18(9):2757-68.

20. Santos MA, Moscheta MS, Peres RS, Rocha FP. Atuação em Psico-Oncologia: atenção multidisciplinar a mulheres mastectomizadas. In: Paulin CS, Melo-Silva LLS, Santos MA, editores. Formação em psicologia: desafios da diversidade na pesquisa e na prática profissional. São Paulo: Vetor; 2005. p. 379-94.

21. Scorsolini-Comin F, Vilela-Souza L, Santos MA. Tornar-se psicólogo: experiência de estágio de Psico-oncologia em equipe multiprofissional de saúde. Rev Bras Orientac Prof. 2008; 9(2):113-25. 
22. Kovács MJ. Sofrimento da equipe de saúde no contexto hospitalar: cuidando do cuidador profissional. Mundo Saude. 2010; 34(4):420-9.

23. Kovács MJ. Espiritualidade e psicologia: cuidados compartilhados. Mundo Saude. 2007; 31(2):246-55.

24. Espíndula JA, Valle ERM, Ales-Bello A. Religião e espiritualidade: um olhar de profissionais de saúde. Rev Lat Am Enfermagem. 2010; 18(6):1229-36.

25. Freitas IS, Oliveira-Cardoso EA, Santos MA. Spirituality and religiosity in mothers of children with hematologic cancer. Psicol Estud. 2017; 22(3):433-47.

26. Mazer-Gonçalves SM, Valle ERM, Santos MA. Significados da morte de crianças com câncer: vivências de mães de crianças companheiras de tratamento. Estud Psicol (Campinas). 2016; 33(4):613-22.

27. Benites AC, Rodin G, Leite ACAB, Nascimento LC, Santos MA. The experience of spirituality in family caregivers of adult and elderly cancer patients receiving palliative care: a metasynthesis. Eur J Cancer Care. 2021; 30(4):e13424.

Palliative care (PC) in Brazilian National Health System (SUS) should be provided in a comprehensive and multidisciplinary manner at the interface between service users, families, carers and the health team, addressing human finitude. The aim of this study was to describe meanings about caring in settings of death and dying produced by psychologists working with PC in the SUS. We conducted a qualitative study drawing on social constructionism and inspired by the description of meanings from everyday life. We interviewed four psychologists working in home care, outpatient PC and hospital care. Two core themes were developed: work processes and their reverse; and close to death and dying. The findings show the importance of team working in self-educational processes, the challenges of working with death and dying in the face of everyday limitations, and critical and reflective constructions of work that promote mental health.

Keywords: Occupational health. Health professional. Palliative care. Mental health. Public health.

Cuidados paliativos (CPs) en el Sistema Brasileño de Salud (SUS) deben realizarse de modo integral y multidisciplinario en el interfaz con usuario, familia, cuidadores y equipo en la aproximación de la finitud humana. El objetivo fue describir los sentidos sobre el cuidar en los escenarios de la muerte y del morir, producidos por psicólogos que trabajan con CPs en el SUS. Se trata de una investigación cualitativa construccionista social inspirada en la descripción de la producción de sentidos del cotidiano. Fueron entrevistados cuatro psicólogos que actuaban en atención a domicilio, ambulatorio de CP y atención hospitalaria. Se construyeron dos ejes temáticos: Los procesos de trabajo y sus contrarios; En las proximidades de la muerte y del morir. Se destaca la importancia del trabajo en equipo en los procesos auto-formativos, los desafíos del trabajo con la muerte y el morir ante las limitaciones del cotidiano y construcciones críticas y reflexivas del trabajo que promueven en salud mental.

Palabras clave: Salud del trabajador. Profesional de salud. Cuidados paliativos. Salud mental.

Salud Pública. 